\title{
Pemberdayaan Anak-anak Panti Asuhan Yayasan Islam Media Kasih melalui Metode Perbanyakan Tanaman Buah dengan Teknik Okulasi dan Penanaman Tanaman Buah di Lingkungan Panti Asuhan
}

\author{
Fadlan Hidayat*, Lukmanul Hakim, Rita Sunartaty, Juliani \\ Program Studi Teknologi Pangan, Universitas Serambi Mekkah \\ Jl. Unmuha, Batoh, Banda Aceh, kode pos 23245 \\ *penulis korespodensi: fadlanhidayat@serambimekkah.ac.id
}

\begin{abstract}
The Islam Media Kasih Orphanage is located in Seutui Village, Baiturrahman District, Banda Aceh City. The amount of children living in the orphanage is fifty people, from Under Five Years (Toddler) to High School (SMA) levels. Community service activities carried out at the Orphanage aim to provide knowledge and assistance at the high school level. The implementation of the activity was carried out by two methods: The first method the implementation team delivered material on the propagation of fruit plants by grafting buds techniques and the second method of the direct practice of grafting techniques exemplified by the implementation team, then followed by the orphans supervised by the team to better understand the techniques grafting in accordance with the material that has been submitted. They were very enthusiastic about participating in the activity from the begining up to the material to the practice of grafting and planting fruit trees, with the hope that the orphans would be able to do it independently.
\end{abstract}

Keywords: Vegetative, Training, Accompany, Food

\begin{abstract}
ABSTRAK
Panti Asuhan Islam Media Kasih terletak di Gampong Seutui Kecamatan Baiturrahman Kota Banda Aceh. Jumlah anak-anak yang tinggal dipanti tersebut sebanyak lima puluh orang, dari Bawah Lima Tahun (BALITA) sampai jenjang Sekolah Menengah Atas (SMA). Kegiatan pengabdian kepada masyarakat yang dilakukan di Panti Asuhan bertujuan untuk memberikan ilmu pengetahuan dan pendampingan pada tingkat Sekolah Menengah Atas. Pelaksanaan kegiatan tersebut dilakukan dengan dua metode : Metode pertama tim pelaksana menyampaikan materi tentang perbanyakan tanaman buah dengan teknik okulasi dan metode kedua praktek langsung teknik okulasi yang dicontohkan oleh tim pelaksana, kemudian diikuti oleh anak-anak panti yang diawasi oleh tim agar lebih memahami tentang teknik okulasi yang sesuai dengan materi yang telah disampaikan. Mereka sangat antusias mengikuti kegiatan tersebut dari awal penyampaian materi sampai dengan melakukan praktek teknik okulasi dan penanaman tanaman buah, dengan harapan anak-anak panti dapat melakukan secara mandiri.
\end{abstract}

Kata Kunci: Vegetatif, Pelatihan, Pangan 
Fadlan Hidayat, dkk

\section{PENDAHULUAN}

Kebutuhan pangan perlu didukung dengan ketersediaan tanaman pangan yang memadai, demikian pula dengan yang tidak termasuk pokok pangan seperti buahbuahan sebagai pelengkap menu makan. Oleh karena itu perlu melakukan peluasan penanaman tanaman buah, untuk mencapai hal itu diperlukan persiapan pembibitan yang baik dalam hal kuantitas maupun kualitas yang akan dikembangkan secara okulasi.

Kunci keberhasilan penerapan teknik okulasi yaitu tenaga okulasi yang terampil dan penyiapan tunas. Penyediaan tunas unggul juga menjadi alternatif meningkatkan kualitas tanaman buah (Boerhendhy, 2013).

Tanaman perkebunan dan hortikultura merupakan komoditas pertanian yang cukup luas yang mencakup buah-buahan, sayur-sayuran dan bunga. Penurunan kadar air berpengaruh terhadap menurunnya kemampuan sel pada tunas membelah dan berdiferensiasi membentuk daun, sehingga lebih cepat bertunas dan sel akan bekerja secara optimal (Pangastuti, Bintoro, \& Duryat, 2018).

Pertumbuhan tunas ditentukan oleh adanya interaksi zat-zat pengatur dan penghambat tumbuh yaitu auksin dan sitokinin. Hormon sitokinin mempunyai peran yang penting pada pembentukan cabang lateral, karena sitokinin yang terdapat pada ujung akar akan ditransport secara akropetal melalui bagian xilem ke bagian atas tanaman (Pratomo, Hanum, \& Putri, 2016).

Dari uraian diatas maka Jurusan Teknologi Pangan Fakultas Teknologi Pertanian Universitas Serambi Mekkah bermitra dengan Panti Asuhan Yayasan Islam Media Kasih yang terletak di Gampong Seutui Kecamatan Baiturrahman Kota Banda Aceh dalam melaksanakan kegiatan pengadian kepada masyarakat terkait dengan perbanyakan tanaman buah secara vegetatif dengan teknik okulasi dan melakukan penanaman tanaman buah disekitar lingkungan panti.

Perbanyakan tanaman secara vigetatif dengan teknik menempelkan tunas (okulasi) yang bertujuan untuk menghasilkan pertumbuhan dan produksi yang baik. Untuk meningkatkan produksi tanaman buah yang berkualitas tergantung pada kualitas bibit dan kultivar tanaman tersebut.

Pertumbuhan pada okulasi dimulai dengan adanya pertautan antara tunas dan batang, selanjutnya terbentuk tunas yang mengawali perubahan bentuk tanaman menjadi individu baru (Sariningtias, Poerwanto, \& Gunawan, 2015).

Okulasi dorman dan waktu tumbuh tunas tidak berpengaruh (Suharsi, Dian, \& Sari, 2013). Untuk mendapatkan mata okulasi dengan juvenilitas yang baik maka percabangan harus diatur dan tetap diperhatikan mutu fisiologisnya (Admojo, Prasetyo, Afifah, \& Hadi, 2013). Bibit yang digunakan untuk melakukan perbanyakan secara vegetatif dengan teknik okulasi berpengaruh terhadap produktivitas (Saragih, Sampoerna, \& Islan, 2014).

Biasanya tunas yang ditempelkan dari tanaman buah berkualitas sedangkan batang yang akan ditempelkan mempunyai akar yang kuat. Tanaman buah sering dilakukan teknik okulasi contohnya mangga, alpukat, rambutan, durian (Maloya, 2017).

Kegiatan pengabdian kepada masyarakat yang bertujuan untuk memberikan pengetahuan, pelatihan dan pendampingan kepada anak-anak panti asuhan dalam melakukan perbanyakan tanaman buah secara vegetatif dengan teknik okulasi. 
Diharapkan kepada anak-anak panti asuhan yayasan islam media kasih dapat melakukan perbanyakan tanaman buah baik secara generatif maupun secara vegetatif.

\section{METODE}

Mitra dari kegiatan pengabdian kepada masyarakat ini yaitu Panti Asuhan Yayasan Islam Media Kasih Gampong Seutui, Kecamatan Baiturrahman, Kota Banda Aceh, Provinsi Aceh. Pelatihan ini meliputi penyampaian materi dan praktek mengenai perbanyakan secara vegetatif dengan teknik okulasi.

Materi yang disampaikan mengenai perbanyakan tanaman buah secara generatif dan vegetatif, pada kegiatan ini lebih fokus pemberian materi tentang perbanyakan secara vegetatif dengan teknik okulasi.

Setelah penyampaian materi, selanjutnya dilakukan praktek langsung cara perbanyakan dengan teknik okulasi. Ada beberapa macam teknik okulasi yang dapat diterapkan, yaitu : 1) okulasi biasa (Forkert modification budding), 2) okulasi-T (Tbudding) dan 3) okulasi irisan (chip budding). Tiga macam cara okulasi tersebut dapat dimodifikasikan menjadi beberapa cara yang merupakan hasil pengembangan atau kombinasi dari beberapa cara okulasi yang ada.

\section{HASIL DAN PEMBAHASAN}

Sebelum melaksankan kegiatan pengabdian kepada masyarakat, maka tim melakukan pemetaan tampat, survei dan lokasi pelaksanaan kegiatan. Setelah melakukan survei dan mendapatkan tempat untuk melakukan kegiatan, tim melakukan koordinasi dengan pengelola Yayasan Islam Media Kasih di Gampong Seutui Kecamatan Baiturrahman Kota Banda Aceh.

Kegiatan pengabdian kepada masyarakat dilakukan dengan dua metode, yang pertama metode penyampaian materi. Tim menyampaikan materi mengenai perbedaan mengenai perbanyakan tanaman buah secara generatif dan vegetatif, pada kegiatan ini lebih fokus pemberian materi mengenai perbanyakan secara vegetatif dengan teknik menempelkan tunas (okulasi).

Berdasarkan hasil observasi anak-anak panti asuhan belum pernah mendapatkan ilmu mengenai perbanyakan tanaman buah secara vegetatif dengan teknik okulasi. Sehingga selama kegitan ini berlangsung, anak-anak panti asuhan sangat antusias dalam menyerap materi yang disampaikan. Hal ini terlihat dari banyaknya anak-anak panti yang hadir dalam kegiatan tersebut serta banyaknya meraka yang bertanya dan berdiskusi dengan tim pelaksana kegiatan. Sehingga mereka dengan mudah memahami kelebihan teknik okulasi, bahwa dengan adanya teknik okulasi persen keberhasilan lebih tinggi, pertumbuhan lebih cepat dan menghasilkan tanaman buah yang berkualitas yang sesuai dengan bibit yang ditempelkan.

Metode yang kedua yaitu memperaktekkan langsung cara perbanyakan secara vegetatif dengan teknik menempelkan tunas (okulasi). Sesuai dengan kesepakatan bersama pada saat penyampaian materi bahwa metode kedua anak-anak panti asuhan mengikuti arahan dari tim pelaksana kegiatan, agar sesuai dengan materi yang telah disampaikan, sehingga pada saat praktek langsung mereka lebih dapat memahami cara melakukan perbanyakan secara vegetatif dengan teknik menempelkan tunas (okulasi). Pada saat praktek langsung anak-anak panti asuhan dengan mudah dan cepat melaksanakannya. Praktek langsung dilakukan dalam polibeg. Okulasi yang dilakukan 
Fadlan Hidayat, dkk

dalam polibeg umumnya digunakan jenis mata sisik. Keunggulan okulasi sisik antara lain, mudah pada saat pelaksanaannya, selain itu persentase keberhasilan lebih tinggi (Junaidi, Atminingisih, \& Siagian, 2014).

Penempelan tunas harus disegerakan tidak boleh ditunda penggunaannya, jika lebih dari satu hari akan memperlambat tumbuhnya tunas dan menurunkan persentase keberhasilan okulasi. Keberhasilan okulasi ditandai dengan kulit mata tempel berwarna coklat atau hijau yang sesuai dengan jenis okulasinya (Hadi, 2010).

Selanjutnya kami berharap dapat bekerja sama dengan pihak mitra panti asuhan yayasan islam media kasih. Sehingga kegiatan pengabdian kepada masyarakat dapat berlanjut dengan topik yang kegiatan yang berbeda. Adapun cara perbanyakan secara vegetatif dengan teknik menempelkan tunas (okulasi) dapat dilihat pada gambar dibawah ini :

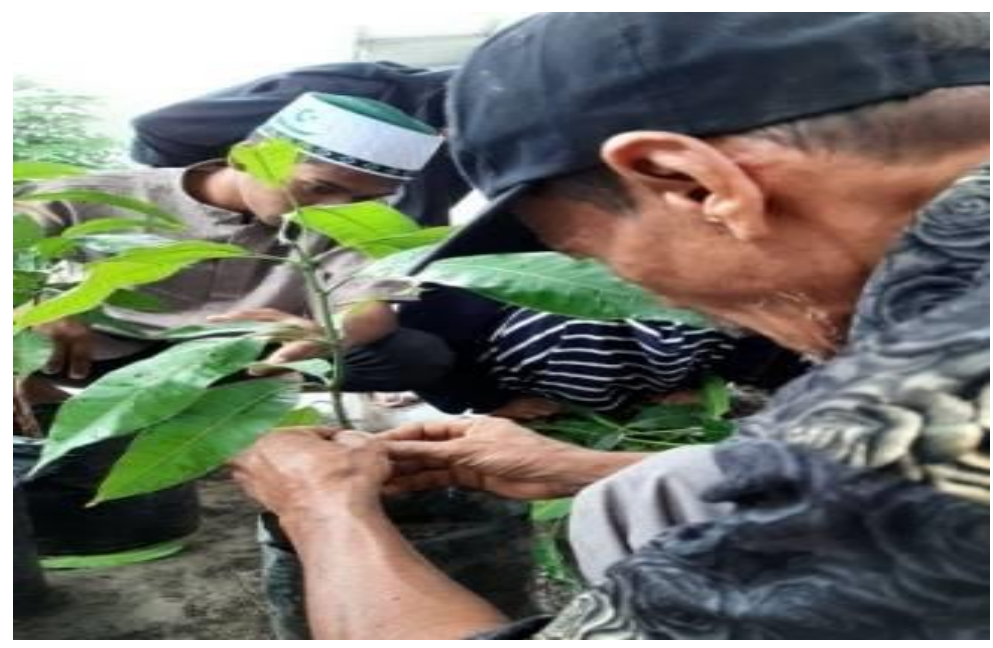

Gambar 1. Teknik Okulasi

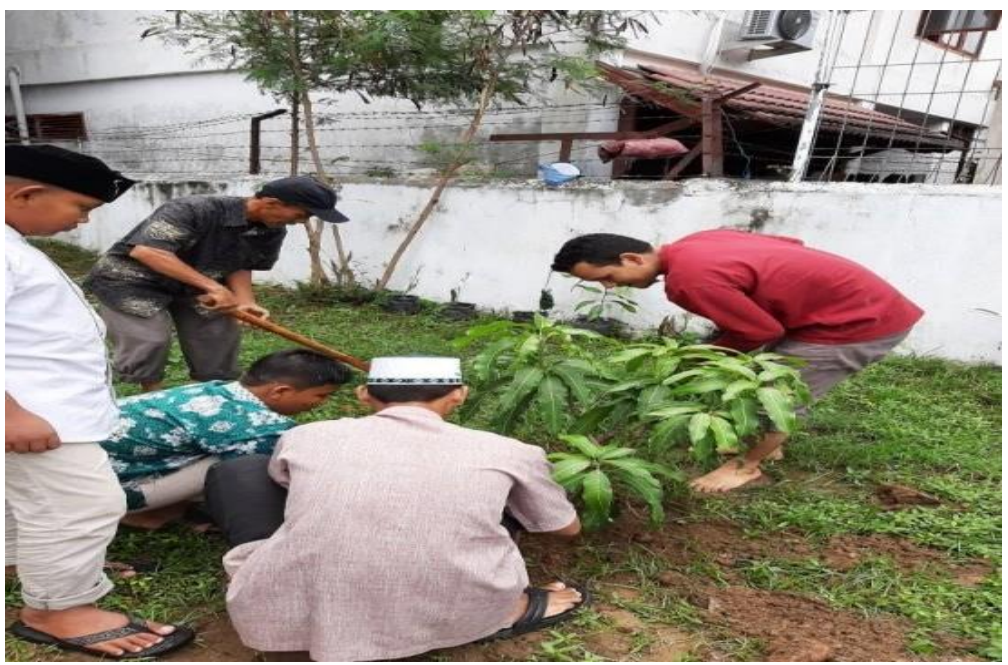

Gambar 2. Penanaman Tanaman Buah 


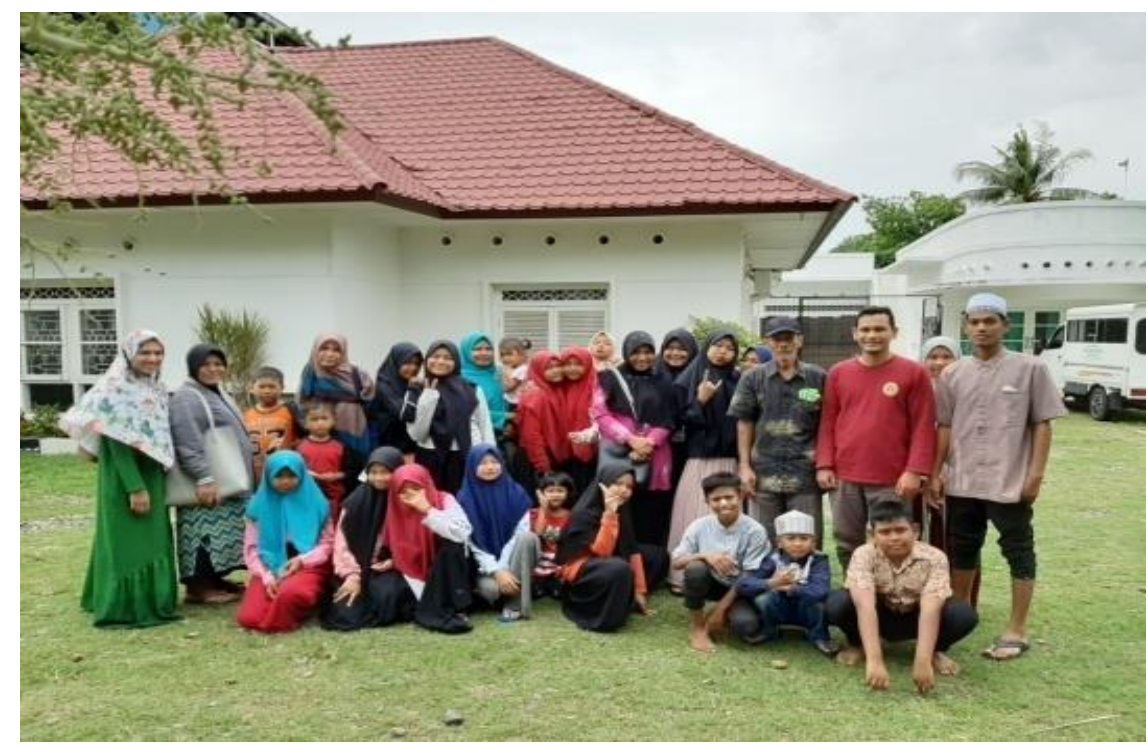

Gambar 3. Foto Bersama Anak-anak Panti Asuhan

\section{KESIMPULAN}

Kegiatan pengabdian kepada masyarkat ini dilakukan oleh Program Studi Teknologi Pangan Fakultas Teknologi Pertanian Universitas Serambi Mekkah bekerja sama dengan panti asuhan Yayasan Islam Media Kasih Gampong Seutui Kecamatan Baiturrahman Kota Banda Aceh. Kegiatan ini dapat bermanfaat bagi anak-anak panti, salah satunya mereka mendapat ilmu dalam perbanyakan tanaman buah secara generatif dan vegetatif. Setelah melakukan praktek langsung bersama, tim pelaksana kegiatan berharap anak-anak panti ashuan dapat melakukan perbanyakan tanaman buah secara vegetatif khususnya dengan teknik okulasi pada tanaman buah dilingkungan panti asuhan secara madiri. Perbanyakan tanaman buah dapat mendukung ketersediaan kebutuhan pangan, sehingga anak-anak panti asuhan dapat memanfaatkan tanaman buah menjadi produk-produk pangan yang dapat dikomersilkan.

\section{DAFTAR PUSTAKA}

Admojo, L., Prasetyo, N. E., Afifah, E., \& Hadi, H. (2013). Pengaruh Juvenilitas Entres Terhadap Karakter Tunas Bibit Okulasi Dini Tanaman Karet. Jurnal Penelitian Karet, 31(1), 13-19.

Boerhendhy, I. (2013). Prospek Perbanyakan Bibit Karet Unggul Dengan Teknik Okulasi Dini. Jurnal Litbang Pertanian, 32(2), 85-90.

Hadi, R. (2010). Teknik dan tingkat keberhasilan okulasi beberapa klon karet anjuran di kebun. Buletin Teknik Pertanian, 15, 39-42.

Junaidi, Atminingisih, \& Siagian, N. (2014). Pengaruh Jenis Mata Entres Dan Klon Terhadap Keberhasilan Okulasi Dan Pertumbuhan Tunas Pada Okulasi Hijau Di Polibeg. 32(1), 21-30.

Maloya, U. (2017). Panduan Lengkap Cara Melakukan Teknik Okulasi. In Dinas Pertanian Dan Ketahanan Pangan Pemerintah Kabupaten Ciamis (pp. 1-2). 
Fadlan Hidayat, dkk

Pangastuti, S., Bintoro, A., \& Duryat, D. (2018). Pengaruh Lama Simpan Entres Jati ( Tectona grandis) Dalam Media Pelepah Pisang Terhadap Keberhasilan Okulasi. Jurnal Sylva Lestari, 6(1), 51. https://doi.org/10.23960/jsl1651-58

Pratomo, B., Hanum, C., \& Putri, L. A. P. (2016). Pertumbuhan Okulasi Tanaman Karet (Hevea brassiliensis Muell arg.) Dengan Tinggi Penyerongan Batang Bawah Dan Benzilaminopurin (BAP) Pada Pembibitan Polibeg. Pertanian Tropik, 3(2), 119-123.

Saragih, N. W., Sampoerna, \& Islan. (2014). Pertumbuhan Bibit Karet (Hevea brasiliensis) Okulasi Pada Media Campuran Subsoil Dengan Pupuk Organik. 41(2), 57-63.

Sariningtias, N. W., Poerwanto, R., \& Gunawan, E. (2015). Penggunaan Benzil Amino Purin (BAP) pada Okulasi Jeruk Keprok (Citrus reticulata). Jurnal Hortikultura Indonesia, 5(3), 158. https://doi.org/10.29244/jhi.5.3.158-167

Suharsi, T. K., Dian, A., \& Sari, P. (2013). Pertumbuhan Mata Tunas Jeruk Keprok (Citrus nobilis) Hasil Okulasi pada Berbagai Media Tanam dan Umur Batang Bawah Rough Lemon (C. jambhiri). Jurnal Ilmu Pertanian Indonesia (JIPI), Agustus, 18(2), 97-101. 